\title{
Dynamic Analysis of Free-Piston Stirling Engine/Linear Alternator-Load System- Experimentally Validated
}

M. David Kankam

National Aeronautics and Space Administration

Lewis Research Center

Cleveland, Ohio

Jeffrey S. Rauch

Sverdrup Technology, Inc.

Lewis Research Center Group

Brook Park, Ohio

and

Walter Santiago

National Aeronautics and Space $\overline{\text { Aldministration }}$

Lewis Research Center

Cleveland, Ohio

Prepared for the

27th Intersociety Energy Conversion Engineering Conference cosponsored by the ANS, SAE, $\overline{A S C}$ AIAA, IEEE, and AIChE San Diego, California, August $\overline{3}-7,19 \overline{9} 2$ 
"Dynamic Analysis of Free-Piston Stirling Engine/Linear

Alternator-Load System - Experimentally Validated"

\author{
M. David Kankam \\ NASA Lewis Research Center \\ Cleveland, Ohio
}

\author{
Jeffrey S. Rauch \\ Sverdrup Technology, Inc. \\ Lewis Research Center \\ Brook Park, Ohio
}

\author{
Walter Santiago \\ NASA Lewis Research Center \\ Cleveland, Ohio
}

\section{ABSTRACT}

This paper discusses the effects of variations in system parameters on the dynamic behavior of a FreePiston Stirling Engine/Linear Atternator (FPSE/LA)-load system. The mathematical formulations incorporate both the mechanical and thermodynamic properties of the FPSE, as well as the electrical equations of the connected load. State-space technlque in the frequency domain is applied to the resulting system of equations to facilitate the evaluation of parametric impacts on the system dynamic stability. Also included is a discussion on the system transient stability as affected by sudden changes in some key operating conditions.

Some representatlve results are correlated with experimental data to verity the model and analytic formulation accuracies. Guidelines are given for ranges of the system parameters which will ensure an overall stable operation.

\section{INTRODUCTION}

The free-piston Stirling engine/linear alternator (FPSE/LA) is an attractive, thermoelectric energy conversion system for space applications due to its potential for long life and reliability. However, when integrated into a power system with connected load(s), system performance must be evaluated to ensure that unfavorable system interactions do not occur. Treatment of such interactions is not commonly found in the existing literature which deals mainly with establishing the engine operating conditions (Refs. 1 to 7 ). Additionally, a combination of detailed representations of the engine thermodynamics and nonlinearities, and load modeling has not recelved widespread attention.

This paper describes a general dynamic analysis of a FPSE/LA connected to a load. The objective of the paper is two-fold. First, the paper demonstrates the application of the state-space technique (Ref. 8) to model the dynamics of a FPSE/LA-load system. This technique is then used to predict the impact of some key system parameters and operating conditions on the dynamic stability of a Space Power Research Englne (SPRE)/Aload system at NASA Lewis Research Center (Ref. 9).

The mathematical model used for the FPSE is based on the recommendations in Ref. 10. The analysis incorporates the engine dynamics and thermodynamics, and detalled modeling of the LA and connected load(s). The state-space formulation used in the analysis is a modern control theory approach of representing a system by its state varlables. By definition, a minimum set of $n$ state variables, typically denoted by " $X$ ", is necessary for a complete description of the internal status or state of the system. The state-space designates the n-variable co-ordinate space in which $X$ ranges. The representation of the system equations by the compact state-space model (SSM) permits the application of powerful vectormatrix theory, and can readily be relegated to a computer to yield a complete description of the system.

The simulation, performed on the MATLAB sottware (Ref. 11), yields results in the form of root locus plots of the system elgenvalues (Ref. 8). The plots show the migration of the system roots caused by parametric variations and, hence, the effects of such variations on the stability margins of the SPRE/A-load system. The advantage of the trequency-domain-based eigenvalue analysis is its single computation of the exact modes of oscllation of the dynamic system. Also, it can complement, valuably, Information obtained by time-domain simulation and testing of a physical system. Many practical systems are nonlinear. However, the usefulness of the linearized eigenvalue analysis is its use in identify. Ing potential worst-case operating conditions which can then be verified by nonlinear time-domain analysis and, possibly, testing. Hence, by using the appropriate input data, the analytic method and results such as reported in this paper can be used to expedite, or assist in, the development of requirements for the application of a FPSE/LA in a space power system. 


\section{STUDY SYSTEM}

The analytic formulations discussed in this paper relate to a system which consists of a single cylinder FPSE connected to an LA via the engine power piston. Figure 1 depicts a block diagram representation of the study system. The LA output terminals in series with a tuning capacitor, $C_{T}$, feed through a load controller to an external load. The controller may be used to "dump" excess generated electric power, in the case where power demand (by the external load) is less than the power supplied by the engine/atternator source. In this case, the load controller acts to maintain power balance. When the load demand exceeds the generated power, the engine will tend to stall.

\section{ANALYTIC APPROACH}

The overall performance equations of the FPSE/LAload system are developed in three stages. First, the equations describing the dynamics of the FPSE are derived. This is followed by the subsystem comprising the LA, parasitic load and an external load. Finally, the combined system equation is formulated for subsequent analysis.

\section{DYNAMIC EQUATIONS OF FPSE}

The following simplifying assumptions are made (1) Schmidt's thermodynamic analysis is evoked such that:

(a) the displacer and piston motions and the working space pressure are sinusoldal

(b) the working fluid obeys the ideal gas law, and expands and compresses isothermally

(2) The working space gas pressure is constant but timevariant.

(3) The bounce space pressure balances the average working space pressure. Hence, average positions of the power piston, displacer and cylinder casing are stationary.

The dynamic equations of the FPSE/LA system, incorporating the mechanical and thermodynamic properties of the Stirling engine, is stated in EQ (1).

$$
\left[M_{M}\right][\ddot{X}]+\left[C_{M}+C_{T}\right][\ddot{X}]+\left[K_{M}+K_{T}\right][X]=\left[F_{E}\right]
$$

where the mechanical system matrices are:

$$
\left[M_{N}\right]=\text { displacer (D) and pistion (P) mass matrix }=\left[\begin{array}{cc}
m_{0} & 0 \\
0 & m_{F}
\end{array}\right]
$$

and $m_{0}$ and $m_{p}$ are the displacer and piston masses. respectively;

and

$$
\left[C_{W}\right]=\text { damping matrix }=\left[\begin{array}{ll}
C_{D D} & C_{D D} \\
C_{D O} & C_{D w}
\end{array}\right]
$$

$$
\left|K_{w}\right|=\text { stifness matrix }=\left[\begin{array}{ll}
K_{n o} & K_{0 D} \\
K_{p 0} & K_{p}
\end{array}\right]
$$

The element $C_{D D}$ is the total damping coefficient of the displacer; that is, the sum of the displacer -to -engine casing (or ground), $C_{D}$, and the displacer-piston coupling $\mathrm{C}_{p \mathrm{p}}$. Similarly, the total piston damping $\mathrm{C}_{\mathrm{pp}}$ comprises the self term $C_{p}$ and piston-displacer coupling $C_{D p}$. These definitions also apply to the stiffness matrix, $\left[K_{M}\right]$. The external force vector $\left[F_{E}\right]$ consists of the displacer and piston components $F_{E D}$ and $F_{E P}$, respectively. Typically, $F_{E D}$ is nonexistent.

The matrices $\left[C_{T}\right]$ and $\left[K_{T}\right]$ are associated with the engine thermodynamic force vector $\left[F_{T}\right]$ expressed in EQ 2. The negative sign denotes the restoring nature of the force $\left[F_{T}\right]$.

$$
\left.\left[F_{\mathrm{r}}\right]=-\left[\mid C_{\mathrm{r}}\right][\dot{x}]+\left[K_{\mathrm{T}}\right][X]\right\}
$$

The details of derivations of the engine equations are documented in Ref. 12. The force $\left[F_{T}\right]$ is expressed in EQ (3), where $A_{D}, A_{A}$ and $A_{p}$ are the displacer, displacer rod and piston areas, respectively. The parameter $P_{c}$ is the compression space pressure on the displacer and piston. The term $P_{H X}$ is the heat exchanger pressure difference between the expansion pressure $P_{E}$ and $P_{F}$. The displacer and piston components of $\left[F_{T}\right]$ are $F_{T D}$ and $F_{T p}$, respectively.

$$
\left.\left[F_{H}\right]=\left[\begin{array}{c}
F_{T D} \\
F_{T M}
\end{array}\right]=\left[\begin{array}{cc}
+A_{D} & -A_{A} \\
0 & -A_{D}
\end{array}\right]\left[\begin{array}{c}
P_{M K} \\
P_{C}
\end{array}\right]-\mid A_{H}\right]\left[P_{H}\right]
$$

The thermodynamic pressure $P_{T}$ is assumed a linearly dependent function mainly of position and velocity. Hence, EQ (3) may be recast into EQ (4), where the superscript $P$ denotes partial derivatives of the pressure terms in EQ (5).

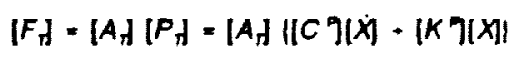

Comparison of EQS (2) and (4) implies the relationship of EQ (6).

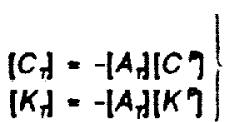


Equation (5) requires that each of $P_{\mathrm{Hx}}$ and $P_{c}$ must be a continuous function of the piston position and velocity.

\section{EVALUATION OF $\left[K^{P 1}\right.$ AND $\left[C^{P}\right]$}

The matrices $\left[K^{+}\right]$and $\left[C^{\circ}\right]$ and, hence, $\left[K_{T}\right]$ and $\left[C_{T}\right]$ may be obtained from Schmidt's thermodynamic analysis. However, this leads to an optimistic prediction of engine performance, since Schmidts's analysis neglects the thermodynamic and fluld frictional losses. Better estimates of the $\left[K^{+}\right]$and $\left[C^{+}\right]$matrices may be evaluated from a more inclusive analysis inherent in the GLIMPS (Rels. 13 and 14) and HFAST (Ref. 15) design codes, or test data.

The pressure terms $P_{c}$ and $P_{\text {Hx }}$ are obtalnable from the design codes, for given piston and displacer positions and speeds. For any Stirling engine, the partials in EO (5) are constant with respect to the engine dynamics and, thus, can be frozen in analytic computations. Additional simplifying assumptions are that the partials $\frac{\partial P_{c}}{\partial X_{0}} \frac{\partial P_{c}}{\partial X_{p}}, \frac{\partial P_{N \alpha}}{\partial X_{0}}$ and $\frac{\partial P_{N \alpha}}{\partial X_{p}}$ are all negligible. Substitution of the reduced EQ (5) into EQ (4) results in EQ (7), in

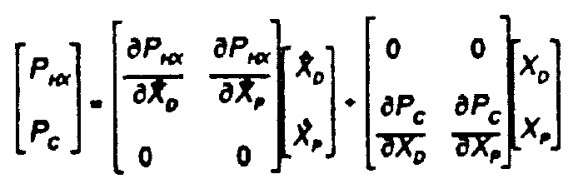

which the pressure, position and speed terms are complex, and can be obtained from the aforementioned design codes or test. Equation (7) yields a total of four real and imaginary equations from which the real-only partials are solved. Subsequently, EQS (8) are obtained from EQ (6) and the resulting EQ (5). The expanded dynamic EQ (9) results from EOS (1) and (8).

$$
\begin{aligned}
& {\left[C_{n}=\left[\begin{array}{ll}
C_{711} & C_{n 2} \\
C_{m 1} & C_{m 2}
\end{array}\right]=\left[\begin{array}{cc}
-A_{0} \frac{\partial P_{m 1}}{\partial X_{0}} & -A_{0} \frac{\partial P_{n \alpha}}{\partial X_{p}} \\
0 & 0
\end{array}\right]\right.}
\end{aligned}
$$

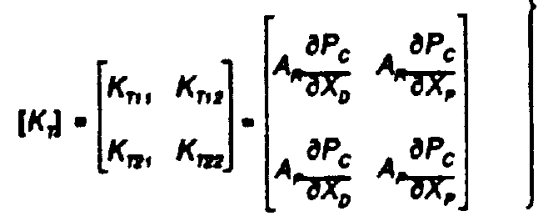

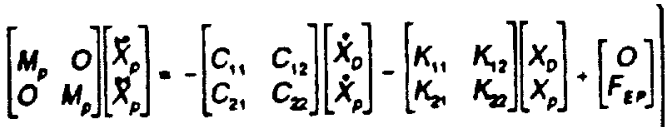

$$
\begin{aligned}
& \text { where }
\end{aligned}
$$

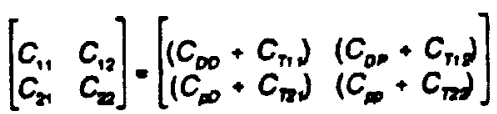

$$
\begin{aligned}
& {\left[\begin{array}{ll}
K_{11} & K_{12} \\
K_{n 1} & K_{n}
\end{array}\right]=\left[\begin{array}{ll}
\left(K_{\infty 0}+K_{r 1}\right) & \left(K_{\infty \infty}+K_{n-2}\right) \\
\left(K_{\infty}+K_{n d}\right) & \left(K_{\infty}+K_{n d}\right)
\end{array}\right]}
\end{aligned}
$$

Thermoelectrlc power generation requires connection of the FPSE to an electromechanical device, such as a linear alternator and an associated load. Modelling of the altemator-load system is discussed next.

\section{ELECTRICAL EQUATIONS OF LA-LOAD MODEL}

An equivalent circult diagram of the LA is shown in Fig. 3. The alternator output terminals are connected through a serles tuning capacitor $C_{Y}$ to a parallel combination of a parastic load $R_{p}$ and an external serles $R_{L} \cdot L_{L}-C_{L}$ static load. The capactor $C_{T}$ serves to ensure an electrical resonance within the circult and. hence, a maximum power transfer from the enginealtemator system to the connected load. The stablity of the system may be enhanced by ensuring a coincidence or near coincidence of the electrical resonant and the mechanical operating frequencies. The other parameters In the figure are the stator resistance, $R_{b}$ the leakage Inductance, $L_{0}$, the magnetizing inductance, $L_{m}$ and the oddy current and hystersis loss form $\mathrm{P}_{c}$ in the magnetic core of the LA.

Application of Kirchhoff's voltage law to loops 1 through 3 yields EQS (10) to (12) in which the term I denotes $\frac{d f}{d f}$ and.

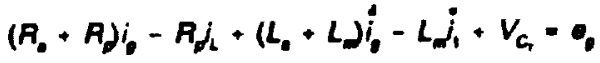

$$
\begin{aligned}
& R_{c_{1}}-L_{j_{1}}+L_{j_{1}}=0 \\
& -R_{b_{b}}+\left(R_{p}+R_{1}\right)_{l}+L_{l_{l}}+V_{c_{c}}=0
\end{aligned}
$$

in terms of the engine plston-Induced flux change, the generated altemator voltage is:

$$
\cdot=-\left(N \frac{\infty}{d x_{p}}\right) x
$$


The capacitor voltages are stated in EQS (14) and (15).

$$
\begin{aligned}
& v_{c_{t}}=i_{l} / \bar{c}_{t} \\
& v_{c_{1}}=i_{l} / c_{b}
\end{aligned}
$$

The term $\Phi$ is the flux linking the $N$ turns of the LA magnetic material. Solution of EOS (10) to (13) results in the derivative currents summarized in EOSS (16) to (18).

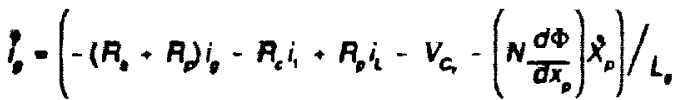

$$
\begin{aligned}
& i=\left(-\left(A_{b}+A_{p}\right) i_{b}+R_{p} i_{L}-V_{c}-\left(N \frac{\partial \Phi}{\partial X_{p}}\right) \hat{x}_{p}\right) / L_{c}-A_{c}\left(\frac{1}{I_{a}}+\frac{1}{I_{m}}\right) i_{1} \\
& i_{L}=\left(\dot{A}_{p} i_{p}-\left(\dot{A}_{p}+\dot{A}_{D}\right) i_{L}-V_{c_{1}}\right) / L_{L}
\end{aligned}
$$

\section{STATE.SPACE REPRESENTATION}

The external force $F_{E p}$ (EO (9)) on the piston is represented by the term $\left.\left(N \frac{\sigma \Phi}{\sigma}\right)\right)_{0}$. The system state variable vector is defined in EQ (19),

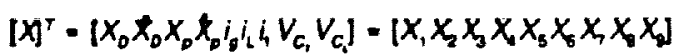

where the superscript " $T$ " denotes transposition of the vector.
Substitution of the state variable EQ (19) into the FPSE dynamic equations (9), and into the LA-load equations (14) to (18) yields the state-space model of EQ (20).

$$
\begin{aligned}
& {[X]=[A][X]+[B](U)} \\
& {[Y=[C] \mid X]+[D \mid U]}
\end{aligned}
$$

The elements of the $9 \times 9$ [A]-matrix of EQ (21) are defined earlier. The selected state variables are all physically measurable and can, therefore, constitute the system outputs $[M]$. Thus, $M$ is $9 \times 1$ vector and the control matrix $[C]$ equals a $9 \times 9$ identity matrix [I]. If the engine oscillation is Initiated by a unity step input to the piston, with subsequent motion of the displacer, then the input vector $\left.[U]^{\top}-\left[U_{0} U_{p}\right]=101\right]$. Hence, $[D]$ is a $9 \times 2$ null matrix.

The matrix $|A|$ contains all the individual and coupled variables of the study system. The damping and stiffness coefficlents contaln the engine nonlinear contributions. However, the matrices [A], $[B],[C]$ and $[D]$ are all numerically constant. Such a linear time-invariant (LTI) system can be subjected to small perturbation analysis about an operating point, to determine the overall system dynamic behavior.

Evaluation of the eigenvalues of the [A]-matrix requires knowledge of all tis elements. The only available set of complete date pertains to the SPRE/LA system connected to an R-L load. The static load is parasitic and mainly resistive whth small but finlte inductance. There is no separate external load as such. Furthermore, the existing data shows no core loss resistance for the altemator model. Imposition of these simplifications on Fig. 3 results in the state variable vector and system matrix as defined in EQS (22) and (23), where the subscript $\mathbf{S}$ denotes simplified electrical model. These equations are used in the analysis of the SPRE/LA-load system.

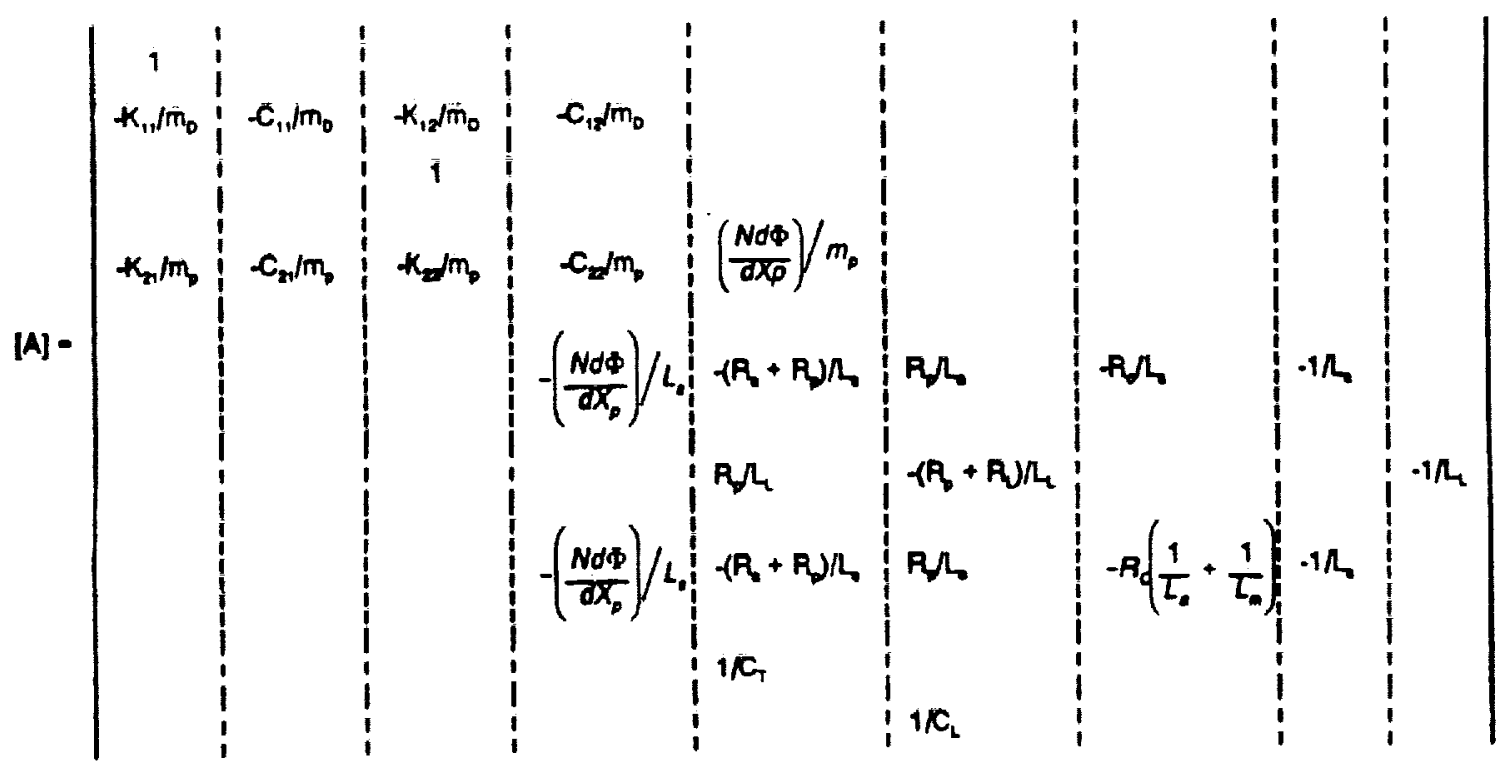




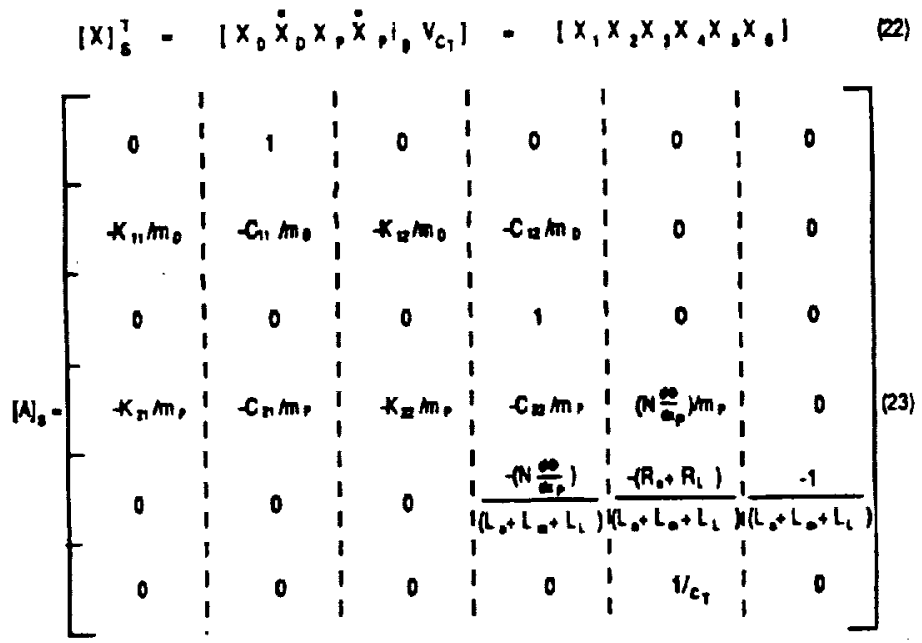

\section{METHOD OF ANALYSIS}

The SSM of the coupled equations are simulated using the MATLAB sotware. Variations are enforced in key system and operating parameters to Induce a migration of the system elgenvalues in the frequency plane. The effect of a parameter on the elgenvalues is determined by varying only that parameter about its nominal or design value, while keeping all other parameters at their nominal values. A plot of the eigenvalue movernent due to changes in a given parameter ylelds the corresponding root locus.

Dynamic analysis derives its strength from its ability to predict the time-domain behavior of an LTI system via simple calculations in the frequency domain. This is exemplified by Fig. 4 (Ret. 16) which shows time histories for corresponding elgenvalues in the trequency domain. The upper part of the plot is typlcally mirrored in the lower half. Exponentially Increasing oscillations are evident for the elgenvalue in the right-hand plane. This dynamic instability, in the case of a FPSE, will be equivalent to a piston overstroke. An elgenvalue on the Jw-axis is critically stable, since the oscillation amplitudes are constant. This is characteristic of, and desired for a FPSE as an oscillator. An elgenvalue in the left-hand plane is dynamically stable. However, a FPSE in this mode of operation is described as stalling or falling our. since the oscillations decay with time.

The foregolng discussions are used to characterize the simulation results.

\section{DISCUSSION OF RESULTS}

The interactions between the FPSERA subsystem and the connected load are illustrated Figs. 5 to 12. The nominal and/or design values of the parameters used in the simulation are summarized in Table 1 which represents the "base" or reference system. All the values shown are measured quantities. However, zero values are enforced for the partials of the heat exchanger pressure with respect to the piston and displacer veloclties. The difficulty associated with measurement of these partials casts doubt on the accuracy of their values. Unless otherwise Indicated, selected parameters are varied from 50 to 150 percent of their nominal value, in Increments of 25 percent. The arrows connecting the "X's" in the plots signify the directions of the elgenvalue movements, due to parametric changes.

BASE SYSTEM - Figure 5 shows a set of eigenvalues for the coupled FPSE/A-load system, and another set for the decoupled FPSE and LA-load subsystems. The electrical and mechanical roots for the coupled base system are identified as $E$, and MP and MD, respectively. The terms MP and MD refer to the plston and displecer elgenvalues, respectively. The terms EU, and MPU and MDU denote the electrical and mechanical roots for the uncoupled FPSE and LA-load subsystems. The uncoupling is realized by setting the $A(5,4)$ and $A(4,5)$ elements to zero In EQ (23) of the simplitied electrical model.

In the case of the uncoupled subsystems, the computed $98.6 \mathrm{~Hz}$ of the electrical root compares nearty exactly with hand-calculated $98.3 \mathrm{~Hz}$ from the characteristhe equation of the electrical subsystem. The average of the predicted piston and displacer frequencles is 107.1 Hz. This ls only 2 percent and 5.8 percent above the design and operating trequencles 105 and $101.1 \mathrm{~Hz}$, respectively, of the SPRE. It is noteworthy that the piston root MPU in the right-hand plane (RHP) is characteristic of an oscillator with exponentially increasing amplitudes towards its mechanical limits. This is consistent with Redlich and Berchowitz's observation (Ref. 2).

The coupled system shows a slight increase in the average engine frequency, namely, $111 \mathrm{~Hz}$. Again, this is within 10 percent of elther the design or operating frequency of the SPRE. Aso, the coupled engine tends 
to reduce the margin of stability of the electrical system. However, the effect of the LA-load subsystem is to push the MPU root to the MP position, nearly on the Jw-axis. Hence, the electrical system acts as an external means of control, and forces the engine to perform as an oscillator. The engine is said to be critically stable in that it osclllates with constant amplitudes. Finally, the unequal piston and displacer frequencies indicate that in the practical engine, the piston stored energy/energy dissipated in a cycle is not necessarily the same as that of the displacer.

The following discussions will highlight the influence of various parameters on the coupled systein roots $E$, MP and MD and, hence, the system dynamic stability.

LA Resistance $\left(R_{a}\right)$ - Varying the alternator resistance from 50 to 150 percent of its nominal value has insignificant effect on the system roots which remain almost stationary in Fig. 6 . The relatively small value of the nominal resistance of $0.082 \Omega$ may account for its ineffectiveness.

LA Leakage Inductence ( $\left.L_{2}\right)$ - A definite effect on the system roots caused by varying $L_{a}$ is evident in Fig. 7 . The symbols " $X$ " of the base system are identified by self. directed arrows from MD, MP and $E$. Increasing $L$ from 50 percent of nominal can place the piston root MP on the jw-axis, while improving the damping of the electrical root $E$. The displacer root gets pushed towards the JWaxis, but remains in the LHP. Further increase in $L$ beyond the nominal value may destabilize the engine, unless this is prevented by some external feedback control system. Thus, the nominal $L$ is considered near optimum for the piston root.

Tuning Capacitance $\left(C_{T}\right)$ - Figure 8 shows that a 50 to 150 percent variation of the nominal tuning capactance has an effect similar to that caused by the leakage inductance. Here, the optimum capacitance for placing the piston root on the $j w$-axis is between 100 and 112 percent of the nominal value.

Load Resistance $\left(\mathrm{A}_{\mathrm{J}}\right)$ - The pronounced impact of the load resistance variation from 50 to 300 percent of its nominal value is illustrated in Fig. 9 . Increasing $\mathbf{R}_{\mathbf{L}}$ significantly improves the electrical demping, with only a modest change in its frequency. The piston root can not only be moved past the jw-axis, but also, its frequency decreases gradually. Initially, the frequency of the displacer root reduces only slightly, while its damping increases. Beyond 150 percent of the nominal $R_{L}$, the damping reduces with further increase in $R_{L}$. Examination of Fig. 9 shows that, as $R_{L}$ increases further, the piston root is pulled into the RHP, while the displecer root moves towards the Jw-axis. These counter-balancing effects will tend to stabilize the engine. Since it is the larger of the two resistances in the system, the load resistance can mask the influence of the LA resistance.
The above observation shows that, generally, a properly designed parasitic load may be used to force the FPSE/LA subsystem to operate as an oscillator; that is, one eigenvalue pair on the $\mid \mathrm{w}$-axis, and all others in the LHP.

Short Circuit Condition - A potentially hazardous operating condition in a FPSE/LA-load system is a short circuit of the load. This represents an extreme case of load impedance variation. Figure 10 depicts the positions of the system roots for such a condition. The electrical root nearly collapses on the jw-axis, without substantial change in frequency. when compared to the base system. With only the small alternator resistance remaining in the electrical circuit, the shorted electrical circuit approximates an oscillator. The piston root is forced into the RHP. signifying exponentially increasing oscillations. Hence. the effect of a sudden short circuit condition is to render the engine unstable, with a possible consequence of piston overstroke. In the physical system, this situation may result from generated energy which is dissipated in a minimum impedance of the electrical system.

Open Circuit Condition - Another possible but undesirable operating scenario is an open circuit condition. This, also, is an extreme form of load inpedance variation. The electrical roots in Fig. 11 collapse onto the origin, with their damping capability eliminated. The engine becomes unstable, as the piston roots are in the RHP. This condition is also possible in a practical system in which the generated energy, in the form of power, abruptly has no path to flow.

\section{CONCLUSIONS}

This paper uses the state-space technique to determine the effects of parametric variations on the dynamic stability of a FPSERA-load system. The mathematical formulation includes the major thermodynamic effects of the engine. The following conclusions are based on the ovaluation of stability of the SPRE/LA-load system. However, the analytical approach and trends of the results are applicable to other FPSENA-load systems.

The results confirm Redlick and Berchowitz's classical control theory-based result that there exists only one mode of oscillation for the FPSE. This mode is denoted by a pair of mechanical roots in the right side of the complex plane. Such roots must be forced by a control mechanism to move onto the jw-axis, to ensure the engine behaviour as a constant amplitude oscillator.

For a given FPSE/LA subsystem, the operating frequency can be load dependent. However, the effect of the constituent load components depends on the their relative magnitudes. A system-designed load generally aids in stabilizing the system. Dynamic stability is reasonably assured, if the electrical system parameters do not change significantly from their design values. For the system studied, the parameters with the most impact 
on the system stablity are the LA leakage inductance, the tuning capacitance and the load resistance.

Abnormal operating conditions, such as a sudden short or open circult of the load, can destabilize the ongine, unless ameliorating controls are in placo.

Generally, the effects of parametric variations on the system dynamic stabllity give an insight into the enginealtemator-load interactions. This information can be valuable during design stage, and with respect to performance prediction to guide system evaluation in experimental work.

\section{REFERENCES}

1. Rauch, J.S., "Steady-state Analysis of Free-Piston Stirling Engine Dynamies," IECEC 75 Record, pp. 961.965.

2. Redlich, R.N., Berchowtz, D.M., "Linear Dynamics of Freo-Piston Stirling Engines," Proc. Instr. Mech. Engrs., Vol. 199, \#A3, pp. 203-213, 1985.

3. Das, R.L. Bahraml, K.A., 'Dynamics and Control of Stipling Engines in a $15 \mathrm{KWe}$ Solar Electric Genoration Concept," Proc. IECEC 1979, pp. 133-138.

4. Benvenuto, G., DeMonte, F., Farine, F., "Dynamic Behavior Prediction of Free-Piston Stirling Engines," IECEC 1990, pp. 346-351.

5. Cichy, M. Carlini, M., "Frequency Dynamic Analysis of Free-Piston Silring Engines," IECEC 1984, pp. 1829-1835.

6. Carlini, M. Kucharski, T., "Dynamic Analysis of FreePiston Stirling Engines by Modal Transformation
Method," Presented at SAE Intl. Congress and Exposition, Detrolt, MI, Feb. 24-2B, 1986.

7. Chen, N.C.J., Griffin, F.P., "Linear Hamonic Analysis of Free-Piston Stirling Engines," ORNLICON-172, Martin Marietta Energy Systems, Inc., Oak Ridge Natl. Lab., June 1986.

8. "Modern Control Theory", Book, by W.L. Brogan, Prentice-Hall Inc., 1982.

9. "Space Power Demonstrator Engine", Phase I Final Report, NASA Contractor Report 179555, May 1987.

10. Kankam, M.D., Rauch, J.S., "Comparative Survey of Dynamic Analyses of Free-Piston Stirling Engines," IECEC, August 1991, Boston/NASA TM-104491, 1991.

11. "MAC II MATLAB," Copyright The Mathwork, 1987. 1988.

12. Rauch, J.S., Kankam, M.D., "Freo-Piston Stirling Engine Dynamics," NASA TM, 1992.

13. Gedeon, D., "A Globally - Implich Stirllg Cycle Simulation," 21st IECEC, Vol. 1, 1986, American Chemical Society, pp. 550-556.

14. Gedeon, D., "GLIMPS Version 4.0 User's Manual," 1992, by Gedeon Assoclates.

15. Huang, S.C., "HFAST.A Harmonic Analysis Program for Stirling Cycles," 27th IECEC, Aug. 1992, San Diego.

16. "Subsynchronous Resonance," Seminar Notes, General Electric Company, 1979. 


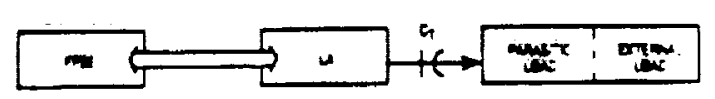

Figure 1. - lock diagram representation ol sludy system.

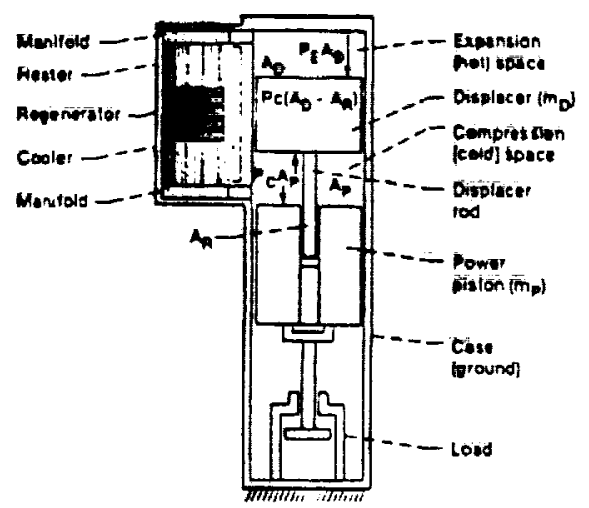

Fig. 2 Schèmatic of a single cylinder Free-Piston Stirling Engine

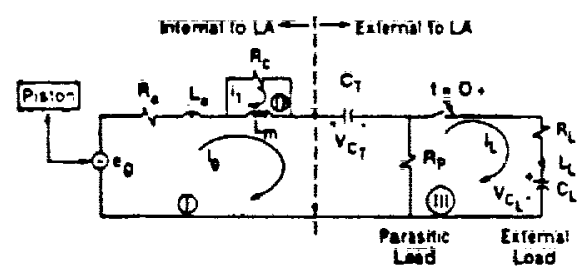

Figure 3. Equivalent circuit of linear alternator (LA)-load system.

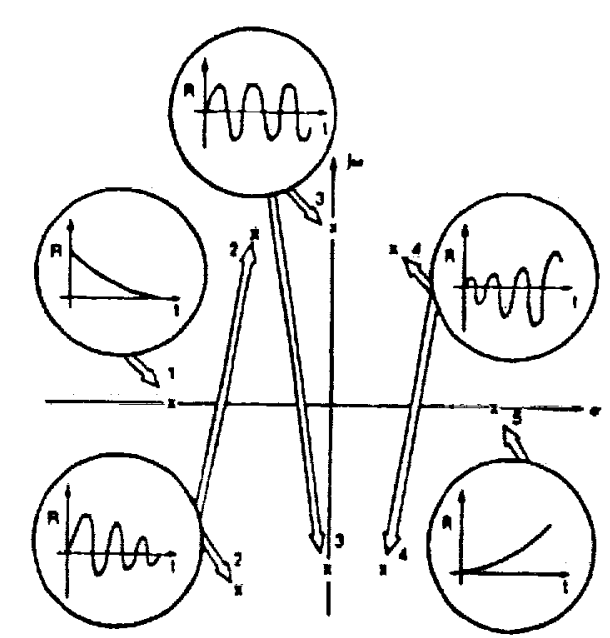

Fig. 4 lllustrating modal responses of eigenvalues

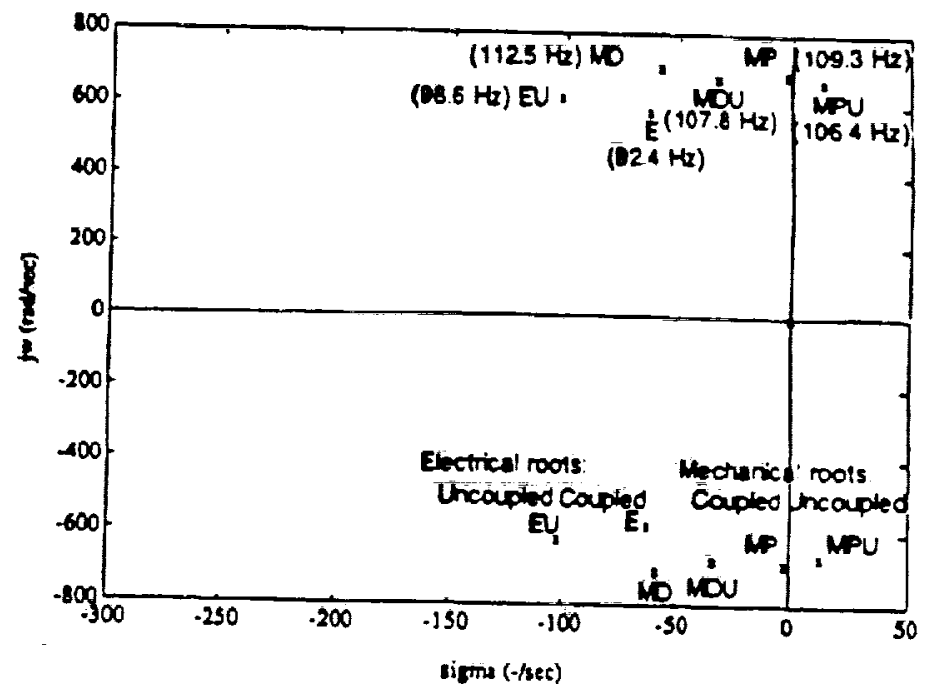

Fig. 5 Plot of coupled and decoupled system oigenvalues

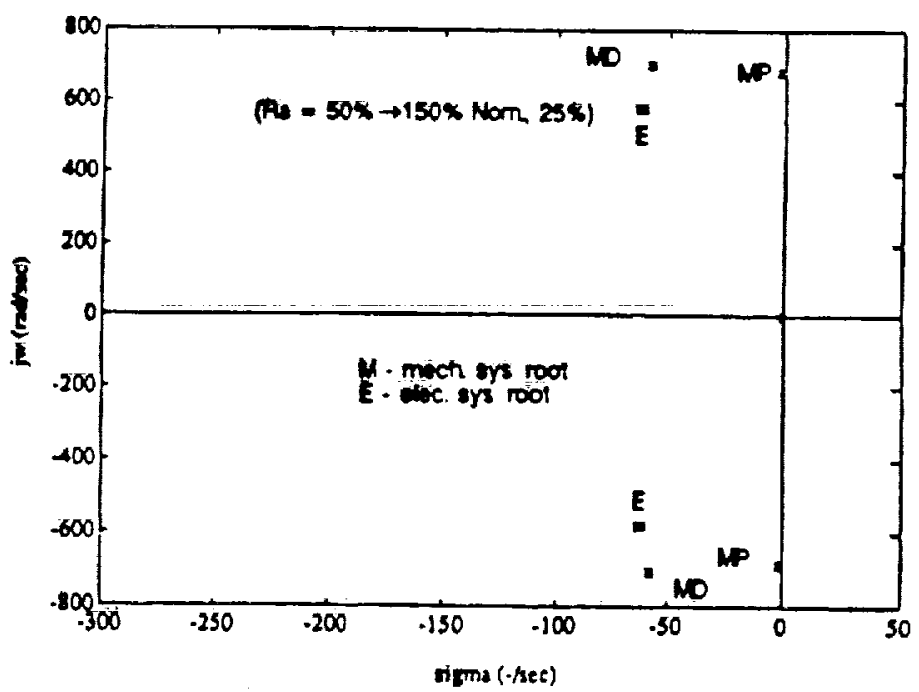

Fig. 6 Plot of system oigenvalues with Ra variation

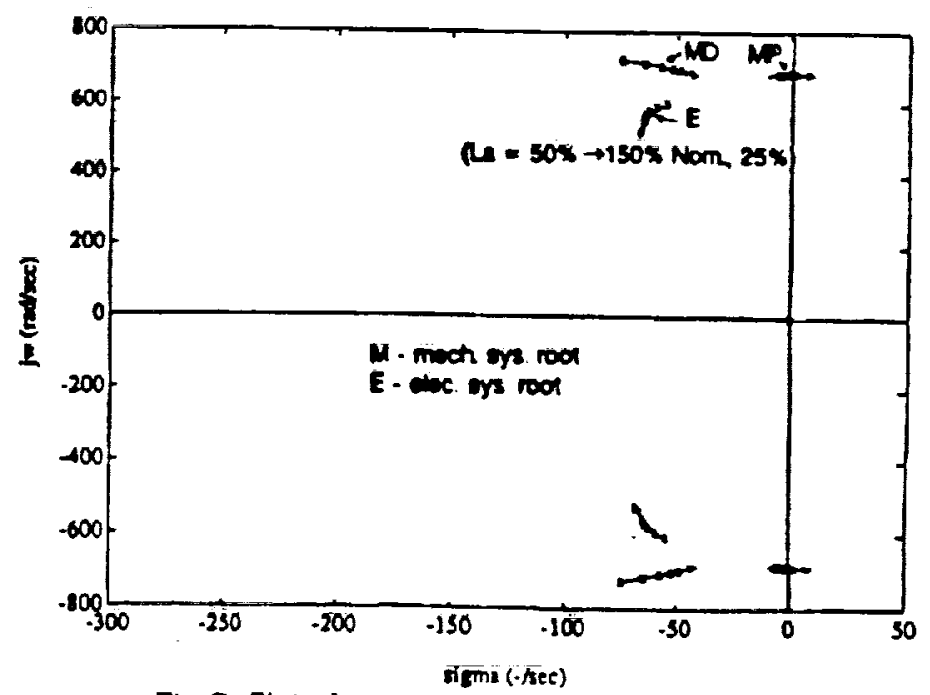

Fig. 7 Plot of system eigenvalues with $L$ variation 


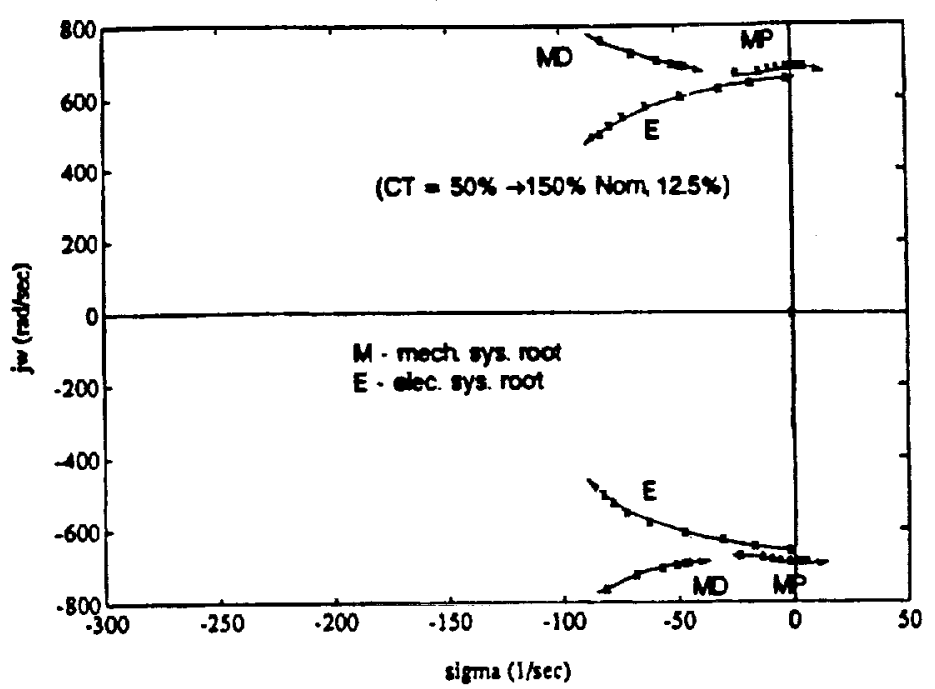

Fig. 8 Plol of system eigenvalues with $C T$ variation

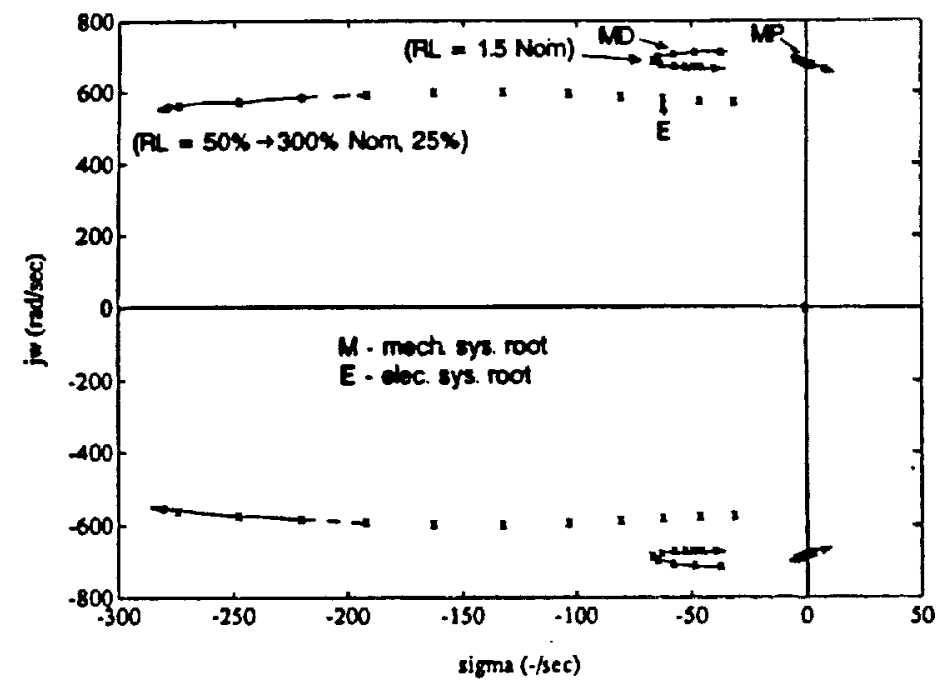

Fig. 9 Plot of system eigenvalues with RL variation

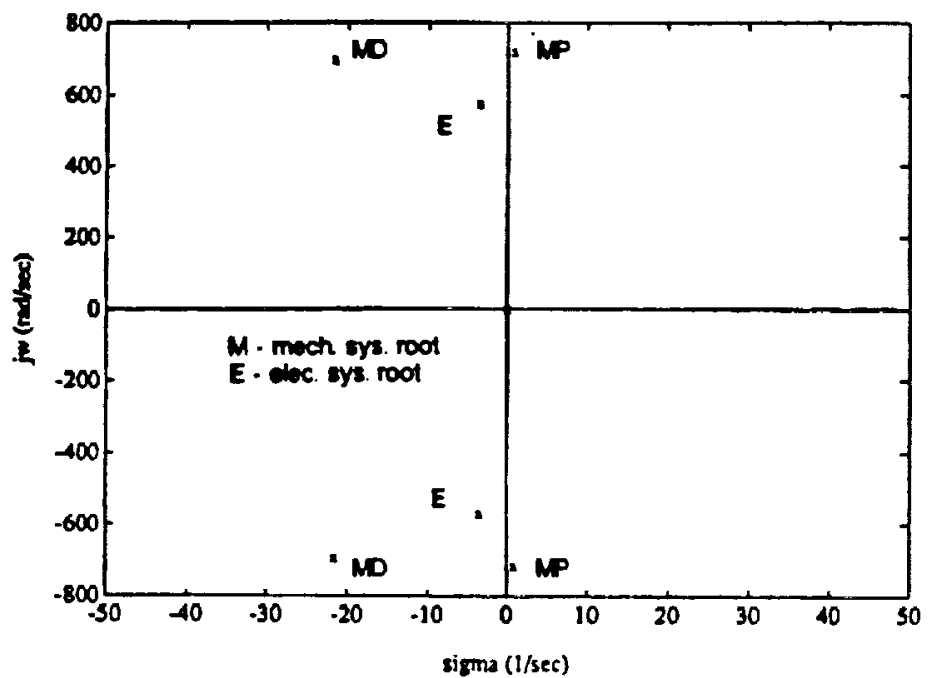

Fig. 10 Plot of system eigenvalues with short circuit

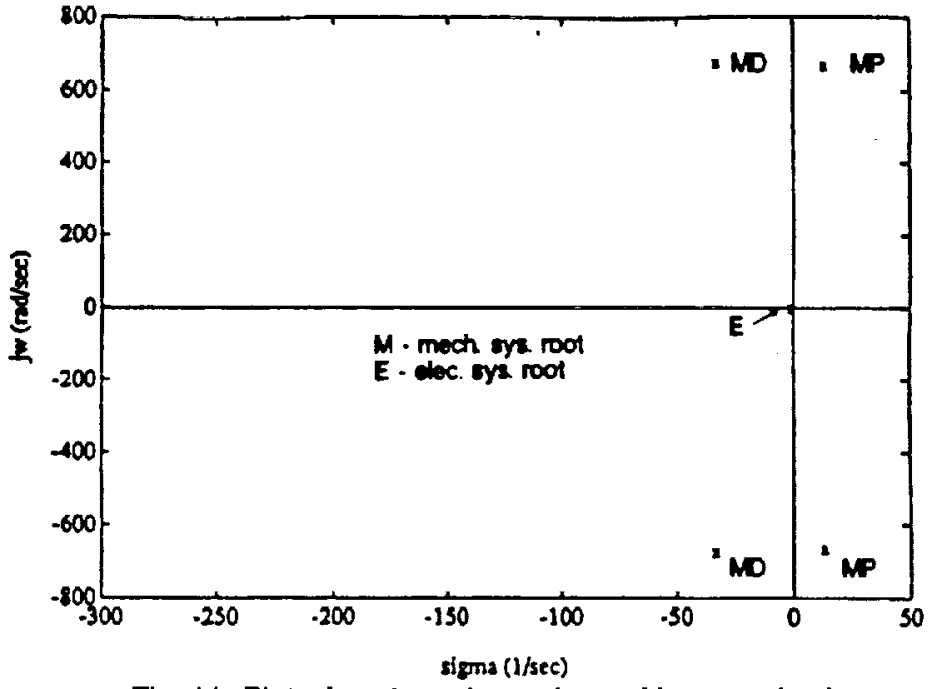

Fig. 11 Plot of system eigenvalues with open circuit

Table 1 Summary of System Parameters

\begin{tabular}{|c|c|c|}
\hline 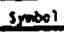 & volue & Bescription \\
\hline in & 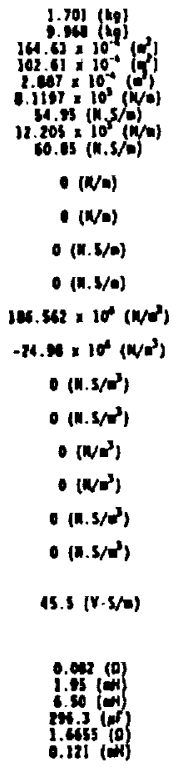 & 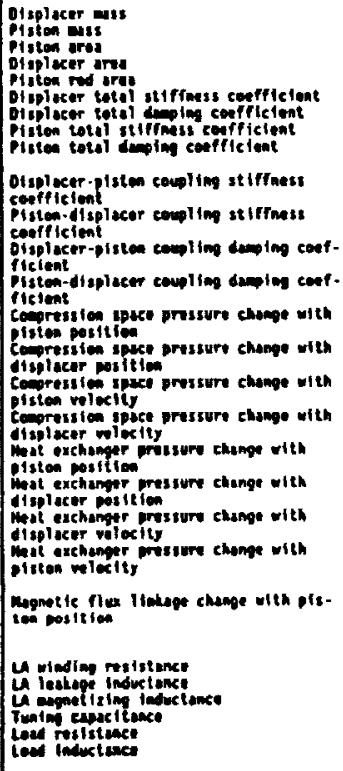 \\
\hline
\end{tabular}




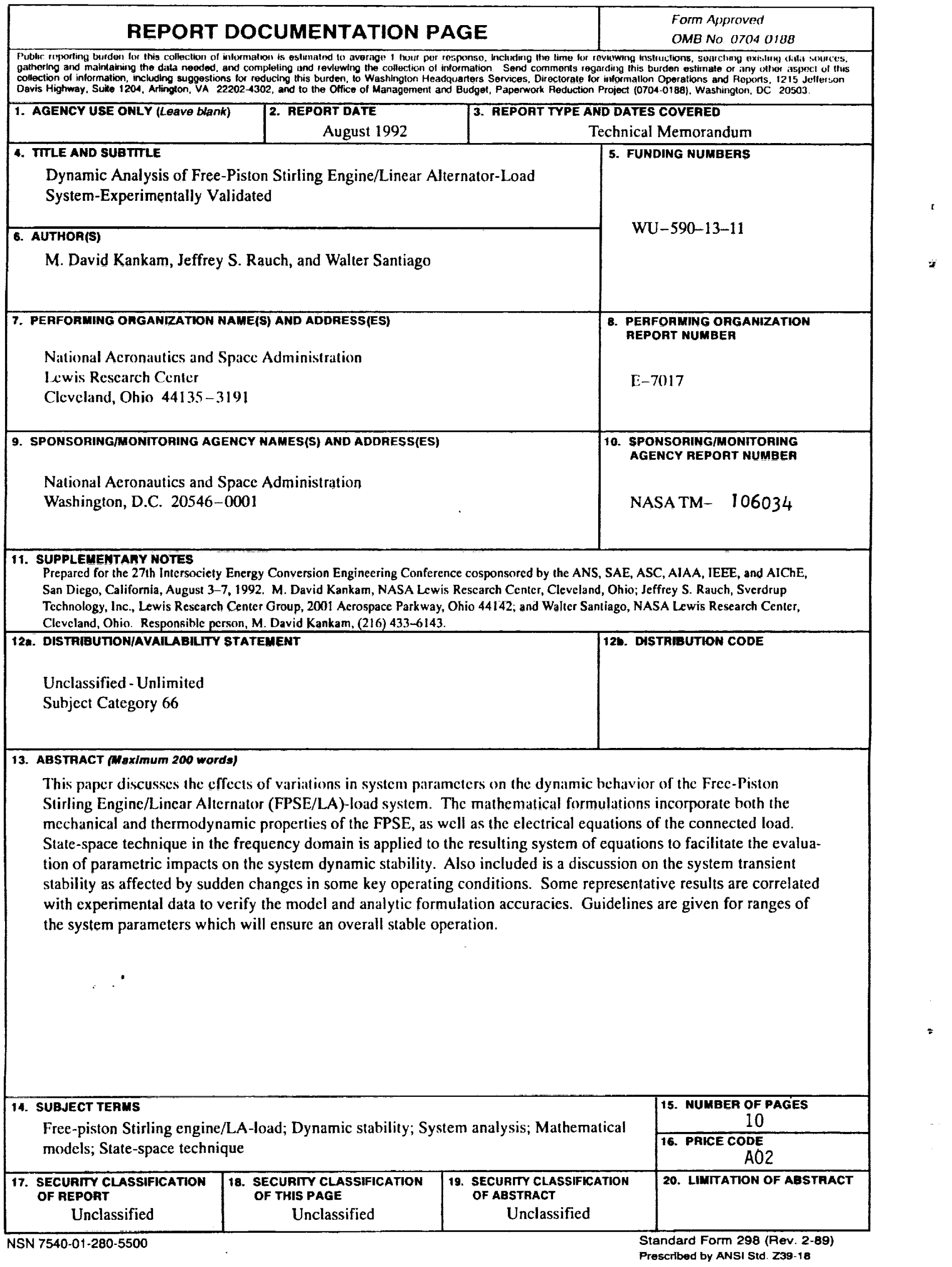

